\title{
Needed Reference Aids
}

IN An attempt to define the needs of 1 reference librarians an inquiry was sent by Clara Van Sant, reference librarian, Tacoma Public Library, to five hundred such librarians requesting an answer to two questions:

I. What reference tools not yet published do you need?

2. What reference projects, aside from tools, would you like to see initiated?

On the basis of frequency of mention four reference projects calling for action were presented at the San Francisco meeting of the A.C.R.L. Reference Librarians Subsection.

\section{Subject Index to Adult Poetry}

John M. Carroll, of the Boston Public Library, spoke as follows on a subject index to adult poetry:

The mention of a subject index to poetry undoubtedly brings to mind the unhappy outcome of the A.L.A. Subject Index to Children's Poetry. It had been for years in preparation and was being carried on according to plans outlined by the A.L.A. Editorial Committee. In 1938 the project was abandoned by the A.L.A. when it was learned that the $\mathrm{H}$. W. Wilson Company had a similar project underway. John B. Brewton, who is compiling the Wilson index, has already indexed some 2 I collections and 250 more are under consideration for inclusion. The date of publication has not been indicated. For a while it had been intended to combine the work of Maud R. MacPherson with that of the A.L.A. index. Of the whole undertaking, her work is the only part that has been published. Her Chil- dren's Poetry Index appeared as Number 62 of the Faxon's Useful Reference Series. She indexed 12,000 poems in 50 anthologies published between I90I and I935. It provides a title and author key as well as a subject index. Although this book was never intended as a general reference tool, we have found it occasionally useful. Since this book has shown itself to be both adaptable and practical, despite its limited sphere, it is hoped that kindred undertakings in other divisions of the field will receive some impetus.

There is at least one project of such a nature now in process. In a recent letter the chief of the Publishing Department of the A.L.A. writes, "A subject index to adult poetry is very nearly completed. We hope to have the manuscript by fall." It certainly does not seem to be unduly optimistic to expect that a worth while publication will appear shortly and that the subject index to adult poetry will disappear from the list of projects underway and will appear on the list of publications. Until this has appeared and been tested, new projects would seem to be out of place, especially with the object lesson of the children's index so fresh in mind.

\section{May Subject Headings Be Voluminous!}

However, I hope that it is not out of place to voice one or two wishes in connection with this undertaking. One to emphasize especially is that of subject headings. May its subject headings be as voluminous as those that appear in the outstanding quotation books! I think that we may expect that this will be the case since the work is being done by a man not only familiar with the standard subject 
headings, but also familiar with the vagaries of the public. One person who has had invaluable experience in this type of work, Louella Everett, has pointed out that such an undertaking would be in the final analysis endless. She prefers relatively few subject headings in her work. It may be interesting to note that Miss Everett is working independently at the present time on a volume that will be more or less a companion to the revised edition of Bartlett, on which she worked with Christopher Morley. But her volume will deliberately include the sentimental, popular, light allusions that people should not want but do. Miss Everett also has underway an anthology of poetry that she has found through experience to be most elusive although steadily called for.

To return to our wishing, I also wish compilers might devise a technique whereby not only general anthologies and certain collections of individual authors but even some elusive fugitive pieces might be analyzed in one listing so that the index would serve not only to suggest material but also help to identify pieces remembered only by their theme. Such will apparently not be the scope of the index now being sponsored. This purpose so easily outlined could only be fully served by a universal index to poetry, but if it should be achieved in any measure it would be a great step forward.

It would be ideal if the compilers were to have time to search out and include material on certain specific topics not necessarily covered by the general anthologies nominated for inclusion. I have in mind certain amusements, sports, vocations and avocations, professions, cultural institutions and so on. Miss Van Sant has already assembled many practical sugges- tions and requests for help on this type of tool. I believe that a certain amount of cooperative effort would be needed at this point in the preparation of such a book. A preliminary edition or at least a prepublication release of the subject headings for which illustrative material had been found might give librarians a chance to consult their "trouble files," and make suggestions and supply material to help round out the book from this angle.

\section{Coordination with Granger}

A last hope is that the compilers will be able to avoid the need of publishing a titleauthor key, although the manuscript for it will undoubtedly be at hand. If the work done on such an index and the scope of Granger's Index could in any way be coordinated, it would be mutually beneficial, both in utility and economy of publishing. The anthologies indexed would not necessarily be all of those located through Granger, but definite duplication, such as holiday material, could be eliminated. A letter from John J. O'Connell, publishing manager of McClurg and Company, reads in part as follows:

Right now we are at the point of completing nearly four years' work on Granger's Index to Poetry, and we realize that a reference of this sort would be invaluable to librarians. However, we are also painfully cognizant of the tremendous labor and time that such an index would represent. ... The matter of a subject key in future editions would necessarily be governed by conditions as they existed at the time of issuing the book. However, it is well within the realm of possibility that we might key our title list in some manner or other to indicate the general subject matter of the poems, together with a reference index at the back of the book, showing which pages might contain such material.

Under any circumstances, a step of this 
sort could not be taken for a number of years... we are loath to commit ourselves.

This letter was dated May ıо, 1939. Since their plans are so very tentative, it would be helpful if some of Granger's material could be made available through an independent index. Of course, unless the selection of titles intended for inclusion in the new edition were made known in a reasonable period of time, the work of the subject index could not be justifiably held up.

There has been much discussion of late of the possibilities of a union list of special indexes. I believe one such survey was made in I9I7. If such a union list had been available, I believe the compilers of the subject index to poetry would have found some of their work already done and available for their use. Over and beyond that, there are maintained files on authors, indexes on special subjects and topics of local interest that could not fall within the scope of a general index to poetry. But a listing of these files might normally be associated with a subject index to poetry, a quite natural extension of its range. A survey of such sources could be conducted without entering the domain of the compilers of the index proper. Is it not possible that an inquiry conducted by a group such as the Reference Librarians Subsection would bring together information that could be organized into a creditable listing of such resources, with the purpose in mind of offering it for incorporation as an appendix to the subject index if the compilers and the Editorial Committee were willing? A general inquiry requesting organizations and individuals to participate voluntarily by sending to a central clearing house a list of files maintained and available for general consultation, or known to be maintained elsewhere, might be the first step. The second step would be a direct mail campaign either to follow up suggestions received through the first survey or to check on institutions that had not responded fully or adequately to the earlier inquiry. This information might be arranged by author, subject or source analyzed, and provided with a subject key of its own, which might or might not be unified with the body of the book. I offer this idea to the subsection for their consideration. Preliminary steps may already have been taken by other agencies of this organization.

\section{Current Biography Service}

Donna L. Root, assistant, Reference Division, Cleveland Public Library, stressed the need for a cumulative bulletin of biography:

IN RESPONSE to the questionnaire regarding needed reference tools that Miss Van Sant sent to reference librarians in February, the Cleveland Public Library general reference division stated that there is a strong need for a cumulative bulletin of current biography. This could be a bulletin or service giving biographical information about names in the news, including their pronunciation. Miss Van Sant wrote that a majority of answers to the questionnaire stressed the need for biographical tools and she asked that our ideas be presented to the reference subsection. She listed various suggestions made by other libraries for a biography tool, most of which can be incorporated in our plan.

Probably the radio has been the most influential factor in causing the increased interest in names in the news. Certainly the stimulus it has given to public speaking has resulted in the need for a reference 
tool which gives correct pronunciation of names to be used by many budding orators. At any rate, our general reference division is continually being asked for biographical sketches of authors of best sellers, journalists, especially foreign correspondents now flooding the market with their comments, political leaders at home and abroad, scientists and physicians, industrial and labor leaders and of course radio and movie stars.

There are many biographical dictionaries which do well for brief sketches and which are reasonably up to date. For the general groups, Who's Who and Who's Who in America, the International Who's Who and the various foreign who's who, come readily to mind. Representative of the special groups are America's Young Men, latest volume 1938-39; American Women 1939-40; American Men of Science, 1938. Then there is the long list of special "who's who's,"-in radio, movies, engineering, etc. 'These volumes might be used to suggest names to appear in the proposed service but the information given is much too brief and is in some cases incomplete and inadequate. Again, these aids are not new enough to include names daily coming to the attention of the reading and listening public.

Our idea is for the publication of a currently issued biographical bulletin or service, giving biographical sketches of present day men and women longer than those in the who's who type of publication. The kind of biographical article published in the Wilson Bulletin, about a page long, with portrait of the subject, is the desired type. A similar sort appears in Authors Today and Yesterday by Kunitz. There is also an excellent French publication which contains this type of sketch-the Dictionnaire National des Contempo- raines. The scope of this service should be international. The determining factor for inclusion would be the prominence of the subject in the news of the day. This might be published in the form of a monthly bulletin, cumulated quarterly, or it might take the form of a loose-leaf service. Europa Company publishes a loose-leaf service which has a European who's who as Volume II. These sketches, however, are the short type.

The English loose-leaf service on current events, Keesing's Contemporary Archives, is closest to what we have in mind. The latter describes itself as "an illustrated weekly diary of world events with index continually kept up to date." A special binder with slide lock holds the sheets in permanent form. This service costs eighteen dollars a year and has the advantage of being extremely timely. We feel there is need of some similar up-to-the-minute service in the field of biography.

\section{Sources of Information}

There are many possible sources which might be used, granting the consent of publishers is obtained.

I. The biographical sketches from the Wilson Bulletin have already been mentioned as an excellent type.

2. Biographical articles in magazines which are indexed in the Readers' Guide could be briefed for inclusion.

3. Sketches of contributors to current magazines could be expanded and used.

4. Publishers' information about authors such as is published on book jackets or in special booklet form. It is our experience that the publishers usually make such information available to the public quite generously, if asked.

5. The column which appears frequently in the Christian Science Monitor 
called, "Pronunciation of Proper Names in the News" is a source both for names to be included and for their correct pronunciation. Since they state that their source is the publisher of Webster's New International Dictionary, it would doubtless be necessary to obtain the cooperation of the G. \& C. Merriam Company.

If something along this line is to be done, it is obvious that a publisher and funds for publication are needed. With this in mind letters were sent to four publishers who might possibly be interested. Two of them responded, asking for further information and showing an encouraging interest. One letter was from Halsey W. Wilson of the H. W. Wilson Company who says: "We have had in mind for some time that there might be opportunity to do something along the line of current reference material in the field of biography." And he goes on to say he will be glad to receive further suggestions. The other letter was from Everett O. Fontaine of the A.L.A. Publishing Department, making useful suggestions for further promotion and financing of the proposal if suitably recommended by the reference section.

We may conclude that there is a definite, expressed need for a reference tool of this sort. If the project is of interest to the reference subsection, it is recommended that further revision and development of the suggested plan be undertaken, in whatever way our chairman, Miss Van Sant, sees fit.

\section{Integration of Reference Review Efforts}

Louis Shores, director, Library School, George Peabody College for Teachers, summarized proposals for a reference journal and offered a recommendation.
THERE ARE now several current publications that review reference materials, and from time to time articles appear in our professional journals that relate to reference methods. Subscription Books Bulletin, issued quarterly, is devoted almost entirely to a critical examination of reference sets sold directly from publisher to consumer. "Current Reference Books," the monthly department in the Wilson Bulletin, restricts itself largely to reference materials sold through the regular trade. Together, these two publications provide a current review of reference materials for popular libraries.

The need for a review of more scholarly reference materials is only partially met by such lists of foreign reference books as appear in the Library Journal, reviews in the Library Quarterly, and in the journals of the respective special fields. It is apparent, therefore, that what is needed is ( I) a popular review of reference materials currently purchased by small libraries, college, public and school, and (2) a scholarly review, that will examine foreign as well at American reference materials of interest to large research libraries.

The following proposals have come to my attention thus far:

1. Expand the Subscription Books Bulletin into a comprehensive reference journal to serve both scholarly and popular needs, under the joint sponsorship of the present Subscription Books Committee and a committee to be appointed by the Reference Librarians Subsection, or constitute the Subscription Books Committee as responsible to the reference subsection.

2. Launch a separate reference journal to be edited by the reference subsection and to include reviews of all types of reference materials. 
3. Include an annual review of new reference books in the College and Reference Yearbook, when, and if, this is revived.

4. Incorporate reviews of reference materials in the Book Review Digest or in the Booklist instead of in a separate, comparatively expensive, publication such as the Subscription Books Bulletin.

5. Bring the Mudge Guide to Reference Books and supplements into a current review scheme which would provide a new Guide at least every five years and a supplement annually.

Since this report was read before the reference subsection, announcement of the new A.C.R.L. journal has been made. In view of this and the above recommendations the following plan intended to utilize existing agencies and to provide an integrated and unified scheme for the evaluation of reference materials is offered:

I. That the American Library Association, Association of College and Reference Libraries, and H. W. Wilson Company pool their resources and provide two popular reviews and one scholarly review of reference materials.

2. That general subscription sets likely to be purchased by school, small public and college libraries be reviewed in the Booklist or in the A.L.A. Bulletin.

3. That non-subscription general reference materials likely to be purchased by school, small public and college libraries be reviewed in the Wilson Bulletin.

4. That all reference materials of interest to the five subsections of the A.C.R.L. be reviewed in the A.C.R.L. journal, particular attention to be given to specialized and foreign tools.

5. That each year the A.L.A. and A.C.R.L. jointly publish a comprehensive list of new reference materials based on
2, 3, and 4, to supplement Mudge's Guide to Reference Books.

6. That each year the H. W. Wilson Company publish an annual selected list of reference materials for the small library.

\section{An Encyclopedia of Sports, Games, and Recreations}

Wilson M. Ranck of the Science and Technology Division, Public Library, Rochester, emphasized the need for a comprehensive encyclopedia of sports, games, and recreations:

THE NEED for a comprehensive encyclopedia in the broad fields of sports, games, and recreations has been commented upon frequently by librarians, physical educators, recreation leaders and others throughout the country. An adequate encyclopedia in this, or any other field, should consider the problem in its broadest aspects and both in relation to its component parts and to its whole. It should include biographical, historical, bibliographical, statistical and sociological data. There should be illustrations, tables, diagrams, and drawings. Bibliographical notations, leading to other and more detailed literature as well as indicating authority for statements, should be considered an integral part of such a work. A copious index is essential. The preparation should be scholarly; its presentation, for the man in the street, that is, popular. An encyclopedia of sports, games, and recreations should include rules and regulations of the activities, techniques of participation and theory. The major articles should be signed by recognized authorities.

The preparation, editing and publishing of a reference tool of this type is a project of considerable magnitude. It will require both moral and financial support. It will 
require good organization. To be properly realized, these aspects must be carefully studied and arranged for in advance. To proceed without adequate support and without preliminary study will mean the production of an inferior tool. Six years have already been devoted to a consideration of this project by the present writer. Opinions have been gathered from many sources. Similar works have been examined. The surface has just been scratched. The desirability of a steering committee to carry on from this point is highly important and advisable.

The sponsorship of an encyclopedia of sports, games, and recreations seems to fall quite logically within the scope of the American Association for Health, Physical Education, and Recreation, a department of the National Education Association. Librarians and their clients, however, will be the largest users and the largest purchasers of any such reference tool. Their needs, their points of view, and their assistance and cooperation are essential for the production of this work. The executive secretary of the physical education group, Dr. N. P. Neilson of Washington, D.C., has suggested having the librarians of the country express themselves as to the need and value of such a work. Further, Dr. Neilson agrees with this writer that the two professional groups have a joint interest and that, therefore, it would be desirable to establish a joint committee representing members of the two organizations, this committee to further the study of the problem and make plans for the definite fulfilment of the idea.

In accordance with the above, the following motion was presented to the Reference Librarians Subsection at San Francisco:

That the Reference Librarians Subsection of the Association of College and Reference Libraries endorse the need for an encyclopedia of sports, games and recreations, that the Subsection recommend to the board of directors of the association the board's endorsement of the need and the board's willingness to establish on behalf of the association, a joint committee with the American Association for Health, Physical Education and Recreation.

It is further moved that an expression of the association's endorsement and willingness to create a joint committee on this subject be forwarded to the American Association for Health, Physical Education and Recreation in Washington, D.C.

After considerable discussion, the subsection voted favorably on the above motions.

Since the action in San Francisco, last June, two publishers of the highest standing have expressed themselves as being definitely interested in this project. 